\title{
Inflammatory and oxidative stress-associated factors in chronic intermittent hypoxia in Chinese patients, rats, lymphocytes and endotheliocytes
}

\author{
HUI REN and KE HU \\ Division of Respiratory Disease, Renmin Hospital of Wuhan University, Wuhan, Hubei 430060, P.R. China
}

Received December 1, 2016; Accepted July 5, 2017

DOI: $10.3892 / \mathrm{mmr} .2017 .7632$

\begin{abstract}
In order to investigate the association between inflammatory and oxidative stress (OS)-associated factors in chronic intermittent hypoxia $(\mathrm{CIH}), 238 \mathrm{CIH}$ patients and 156 healthy volunteers were included. CIH rat and lymphocytes were used as experimental models. Interleukin (IL)-6, tumor necrosis factor- $\alpha$ (TNF- $\alpha$ ), C-reactive protein (CRP), nitric oxide (NO) and nitric oxide synthase (NOS) were analyzed. Patients with $\mathrm{CIH}$ were older, with hypertension, increased heart rate (HR) and body mass index (BMI), and there were more males than females. Those with a history of smoking or type 2 diabetes (T2DM) history exhibited an increased risk of CIH. Serum IL-6, TNF- $\alpha$ and CRP in patients with $\mathrm{CIH}$ were increased, while NO and NOS were decreased. Hakka patients exhibited increased BMI measurements and NO expression, and decreased systolic arterial pressure, IL- 6 and TNF- $\alpha$ compared with non-Hakka patients. Rats with $\mathrm{CIH}$ exhibited hypertension and stable weight, less activity and decreased appetite, increased HR and serum IL-6, TNF- $\alpha$ and CRP, and decreased NO and NOS. IL-6, TNF- $\alpha$, CRP, NO and induced-NOS (iNOS) were increased in the lymphocytes of $\mathrm{CIH}$ rats compared with healthy ones. In rat endotheliocytes induced by $\mathrm{CIH}$, IL-6, TNF- $\alpha$, CRP and iNOS increased, while NO and endothelial-NOS (eNOS) decreased. In the supernatant of co-cultured lymphocytes and endotheliocytes, IL-6, TNF- $\alpha$ and CRP increased, although NO and NOS decreased. In conclusion, age, male gender, BMI, smoking and T2DM history, serum IL-6, TNF- $\alpha$ and CRP were positively correlated with $\mathrm{CIH}$ combined with hypertension, while NO and NOS were negatively correlated with CIH. Serum NO was predominantly synthesized and released by eNOS. Hakka patients exhibited decreased inflammation and OS with $\mathrm{CIH}$.
\end{abstract}

Correspondence to: Dr Ke Hu, Division of Respiratory Disease, Renmin Hospital of Wuhan University, 99 Zhangzhidong Road, Wuhan, Hubei 430060, P.R. China

E-mail: hukewuda@163.com

Key words: inflammation, oxidative stress, obstructive sleep apnea hypopnea syndrome, chronic intermittent hypoxia
Increasing IL-6, TNF- $\alpha$ and CRP, and decreasing NO and NOS are biomarkers of $\mathrm{CIH}$, which could be targets in diagnosis, treatment and prevention of $\mathrm{CIH}$.

\section{Introduction}

The most common type of chronic intermittent hypoxia (CIH) is obstructive sleep apnea hypopnea syndrome (OSAHS), which is characterized by repeated upper airway obstruction and frequently-interrupted breathing during sleep; the condition is potentially life-threatening (1). By enhancing oxidative stress (OS), inflammation and sympathetic nerve discharge, $\mathrm{CIH}$, in addition to sleep structure disorders, may stimulate a series of alterations in the molecular biology of the patient (2).

The majority of patients with OSAHS additionally exhibit hypertension, and more serious sleep apnea is associated with increased hypertension, which is a risk factor for myocardial and cerebral infarction (3). Hypertension has been observed to be highly prevalent in patients with OSAHS, with an incidence of $30-60 \%$ (4). According to previous studies, OSAHS is present in 30-40\% of patients with hypertension (5). Although OSAHS has been categorized as one of the primary factors causing secondary hypertension, the mechanisms of hypertension induced by OSAHS remain unclear. At present, there are numerous processes which have been hypothesized to contribute to hypertension, including abnormal nerve reflex (6), humoral factors (7), vascular endothelial dysfunction (8), inflammation (9) and vascular construction (10).

$\mathrm{CIH}$ is characterized by a low oxygen period, distinct from a normal oxygen period (11). However, CIH, in addition to continuous hypoxia, may induce inflammation. The underlying mechanisms of OSAHS-induced hypertension remain to be elucidated. It has previously been demonstrated that the circulating levels of interleukin (IL)-6, tumor necrosis factor (TNF)- $\alpha$ and C-reactive protein (CRP) are elevated in patients with OSAHS (12-15), indicating that $\mathrm{CIH}$ may be associated with systemic inflammation. In the initiation and progression of hypertension, endothelial dysfunction occurs early, in response to the inflammatory cytokines (16). This process may result in an increase in intercellular adhesion molecules, leading to the promotion of leukocyte adherence to the endothelium, in addition to extravasation (16). Hypertension may subsequently develop. 
Additionally, the hypoxia-reoxygenation cycles during $\mathrm{CIH}$ may induce the production of reactive oxygen species (ROS) and OS (17). Following CIH exposure, endothelin 1 and angiotensin II have been observed to increase due to ROS-mediation, which may enhance chemosensitivity in carotid bodies $(18,19)$, while nitric oxide synthase (NOS) may inhibit chemoreceptor function (20), including endothelial NOS (eNOS) and neuronal NOS (nNOS).

There are numerous individuals belonging to the Hakka population in Guangdong Province (China), and these individuals are generally very careful about their health. Certain common customs within this population, for example, stewing soup for $>2 \mathrm{~h}$, making wine, plum liqueur or snake wine and cooking with less salt or oil, are claimed to be beneficial to health and in reducing diseases. Wine has been confirmed to soften the vasculature and prevent cardiovascular diseases (21), and slow cooking soup has been anecdotally claimed to maintain beauty and good health. However, the incidence of $\mathrm{CIH}$ within the Hakka population has not previously been investigated.

Therefore, the present study aimed to investigate the association between inflammation, OS, CIH and hypertension by comparing the levels of IL- 6 , TNF- $\alpha$, CRP, nitric oxide (NO) and NOS in Hakka patients from Huizhou City with non-Hakka patients. Additionally, $\mathrm{CIH}$ rat models were established and the 5 factors were detected in isolated lymphocytes and co-cultured endotheliocytes.

\section{Materials and methods}

Patients. A total of 238 patients, including 106 Hakka patients and 132 non-Hakka patients, from Huizhou (China), were diagnosed with $\mathrm{CIH}$ combined with hypertension in Nanfang Hospital (Guangzhou, China) between March 2013 and October 2016. A total of 156 volunteers (non-Hakka; from Huizhou) were recruited as healthy controls during the same time periods as the patients. Clinical data including age, sex, weight, systolic arterial pressure (SAP), diastolic arterial pressure (DAP), mean arterial pressure (MAP), heart rate (HR), smoking and type 2 diabetes (T2DM) history were obtained for analysis. Blood samples were obtained at 9:00 a.m. at the initial clinic visit and stored at $-28^{\circ} \mathrm{C}$.

Informed consent was obtained from each patient and volunteer, and the present study was approved by the Medical Ethics Committees of Nanfang Hospital (Guangzhou, China) and Renmin Hospital of Wuhan University (Wuhan, China).

Animals. A total of 10 male Wistar rats (age, 60-70 days; weight, 191.42 $\pm 14.05 \mathrm{~g}$ ) were obtained from Qingdao KangDa Biotechnology Co., Ltd. (Qingdao, China) and housed individually in polycarbonate cages with wire lids, under the conditions of 12 -h light/dark cycle, $22-25^{\circ} \mathrm{C}$ and $50-70 \%$ humidity. Standard laboratory diet and water were supplied freely. The animal welfare and experimental protocols were approved by the Animal Research Ethics Committee of Renmin Hospital of Wuhan University. The experiments were performed in accordance with the National Institutes of Health Principles of Laboratory Animal Care (NIP Publication 85-23, revised 1996), the European Guidelines for the Protection of Animals used for Scientific Purposes (European directive 2010/63/EU) and Portuguese Law no. 113/2013.
CIH models. The 10 rats were randomly divided into 2 groups, control and $\mathrm{CIH}$. Rats in the $\mathrm{CIH}$ group were placed in a dynamic $\mathrm{O}_{2} / \mathrm{N}_{2}$ controller (OxycyclerA84A-chamber; BioSpherix, Ltd., New York, NY, USA) and exposed to $5 \mathrm{~min}$ cycles of $90 \mathrm{sec}$ hypoxia $\left(5 \% \mathrm{O}_{2}\right)$ and $210 \mathrm{sec}$ normoxia $\left(21 \% \mathrm{O}_{2}\right), 8 \mathrm{~h}$ /day for 3 weeks during the light hours. Rats in the control group were exposed to the same environment but with normoxia $\left(21 \% \mathrm{O}_{2}\right)$ maintained $24 \mathrm{~h}$ /day for 3 weeks. The MouseOX pulse oximetry system (Starr Life Sciences Corp., Oakmont, PA, USA) was used to measure the arterial oxygen saturation $\left(\mathrm{SaO}_{2}\right)$ as $\sim 70 \%$, according to the specifications of the instrument.

Hemodynamic analysis. SAP, DAP, MAP and HR in human subjects were measured according to the clinical protocol 'Essential hypertension for primary healthcare level' (22). Hemodynamic analysis in rats was performed using Mouse and Rat Tail Cuff Blood Pressure system and analyzed using the equipped software (3R22931; IITC Life Science, Inc., Woodland Hills, CA, USA), according to the manufacturer's specifications, one day prior to model establishment and at the 7 th, 14th and 21 st days of experimentation.

Serum IL-6, TNF- $\alpha, C R P, N O$ and NOS detection. For patients, blood samples were concentrated at $3,000 \mathrm{x}$ g at $4^{\circ} \mathrm{C}$ for $10 \mathrm{~min}$ and serum was separated. For rats, weights were measured and blood was collected at 9:00 a.m., one day prior to model establishment and on the 7th, 14th and 21st day of experiments. Blood samples were centrifuged at 3,000 $\mathrm{x} \mathrm{g}$ for $10 \mathrm{~min}$ at $4^{\circ} \mathrm{C}$ to separate the serum. ELISA kits for Serum IL-6 (CHC1263, Thermo Fisher Scientific, Inc., Waltham, MA, USA), TNF- $\alpha$ (RAB0340) and CRP (CYT298) (both from Sigma-Aldrich; Merck KGaA) were used. NO and NOS levels were determined using Total Nitric Oxide Assay and Nitric Oxide Synthase Assay kits (Beyotime Institute of Biotechnology, Haimen, China), respectively.

Lymphocyte isolation. The lymphocytes of rats in the two groups were isolated using Ficoll-Histopaque (Sigma-Aldrich; Merck $\mathrm{KGaA}$ ) double density gradient centrifugation. A total of $3 \mathrm{ml}$ Histopaque 1119 was added to a $15 \mathrm{ml}$ tube, and $3 \mathrm{ml}$ Histopaque 1083 was added on top. A total of $6 \mathrm{ml}$ blood sample was added onto the Histopaque 1083, and centrifuged at $700 \mathrm{x}$ g for $30 \mathrm{~min}$. There were 6 levels following centrifugation, including serum, monocytes, Histopaque 1083, neutrophils, Histopaque 1119 and erythrocytes. The serum, monocytes and Histopaque 1083 were discarded to leave the neutrophils at $0.5 \mathrm{~cm}$ thickness. The neutrophils were transferred to a new tube and $10 \mathrm{ml} 1 \mathrm{X}$ PBS was added to wash twice. The tube was centrifuged at $200 \mathrm{xg}$ for $10 \mathrm{~min}$, then the supernatant discarded, and the sample was resuspended with RPMI-1640 (Thermo Fisher Scientific, Inc.) at a density of $1 \times 10^{6}$ cells $/ \mathrm{ml}$. The lymphocytes were cultured with RPMI-1640 containing $10 \%$ fetal bovine serum (FBS; Thermo Fisher Scientific, Inc.) at $37^{\circ} \mathrm{C}, 5 \% \mathrm{CO}_{2}$ and saturated humidity.

Detection of apoptosis rate and IL-6, TNF- $\alpha, C R P, N O$ and iNOS levels in lymphocytes. Isolated lymphocytes in the logarithmic growth phase were used for the following experiments $\left(1 \times 10^{5}\right.$ cells $\left./ \mathrm{ml}\right)$. A propidium iodide staining kit (Beyotime 
Institute of Biotechnology) was used to detect apoptosis in rat lymphocytes, according to the manufacturer's protocol, and the results were observed under a fluorescence microscope at $535 \mathrm{~nm}$. Western blotting was used to detect IL-6, TNF- $\alpha$, CRP and iNOS levels in lymphocytes. Radioimmunoprecipitation assay buffer (Thermo Fisher Scientific, Inc.) was added to the lymphocytes according to the manufacturer's protocol. The cells were incubated on ice for $10 \mathrm{~min}$ and centrifuged at $10,000 \mathrm{x}$ for $10 \mathrm{~min}$ at $4^{\circ} \mathrm{C}$. The supernatant was separated and $5 \mathrm{X}$ loading buffer (Beyotime Institute of Biotechnology) was added. The total protein concentration was determined using a bicinchoninic acid protein quantitation kit (Beyotime Institute of Biotechnology). A total of $40 \mu \mathrm{g}$ protein/lane was separated by SDS-PAGE with a $5 \%$ stacking gel and a $10 \%$ separating gel. The proteins were transferred to polyvinylidene fluoride membranes (Merck KGaA). Rabbit anti-IL-6 (21865-1-AP, 1:2,000), rabbit anti-TNF- $\alpha$ (17590-1-AP, 1:2,000), rabbit anti-CRP (13432-1-AP, 1:2,000), rabbit anti-iNOS (18985-1-AP, $1: 2,000)$, mouse anti- $\beta$-actin (60008-1-AP, 1:10,000) (all from Wuhan Sanying Biotechnology, Wuhan, China) were used to incubate at $4^{\circ} \mathrm{C}$ overnight. The membranes were then incubated with goat anti-mouse IgG HRP (223-005-024) or goat anti-rabbit secondary antibodies (323-005-024, 1:3,000) (both from Jackson ImmunoResearch Laboratories, Inc., West Grove, PA, USA) at $25^{\circ} \mathrm{C}$ for $1 \mathrm{~h}$. Enhanced chemiluminescence (WBKLS0500; Merck KGaA) substrate was used to visualize proteins. Semi-quantification was performed using ImageJ 1.48 (National Institutes of Health, Bethesda, MD, USA). NO detection was performed using the Total Nitric Oxide Assay kit.

CIH induction and detection of IL-6, TNF- $\alpha, C R P, N O$, eNOS and iNOS levels in endotheliocytes. Rat aortic endotheliocytes were obtained from the American Type Culture Collection (RAOEC; Manassas, VA, USA) and cultured in RPMI-1640 with $10 \% \mathrm{FBS}$ at $37^{\circ} \mathrm{C}, 5 \% \mathrm{CO}_{2}$ and saturated humidity. A three-gas incubator (C42; BioSpherix, Ltd.) was used for to induce a $\mathrm{CIH}$ environment with hypoxia $(1.5 \%$ $\left.\mathrm{O}_{2}, 45 \mathrm{sec}\right)$-normoxia $\left(21 \% \mathrm{O}_{2}, 135 \mathrm{sec}\right), 20$ times/h for a total of 60 cycles. Rat endotheliocytes were induced for 1,2 and $3 \mathrm{~h}$.

The IL-6, TNF- $\alpha$, CRP, eNOS and iNOS levels in endotheliocytes were detected by western blotting and NO was detected using the Total Nitric Oxide Assay kit.

Co-culturing of isolated lymphocytes and endotheliocytes. A total of 4 groups were established: CIH-L+CIH-E (CIH rat lymphocytes + CIH-induced rat endotheliocytes); CIH-L+CON-E (CIH rat lymphocytes + endotheliocytes); $\mathrm{CON}-\mathrm{L}+\mathrm{CIH}-\mathrm{E}$ (lymphocytes + CIH-induced rat endotheliocytes); and CON-L+CON-E (lymphocytes + endotheliocytes). Rat lymphocytes $\left(1 \times 10^{5} \mathrm{cells} / \mathrm{ml}\right)$ were added to the rat endotheliocytes $\left(1 \times 10^{5}\right.$ cells $\left./ \mathrm{ml}\right)$ with or without $\mathrm{CIH}$ induction, and co-cultured for $4 \mathrm{~h}$.

Co-culturing supernatant IL-6, TNF- $\alpha, C R P, N O$ and NOS levels detections. Subsequent to co-culturing, the supernatant of the cells was collected. IL-6 (KRC0061C), TNF- $\alpha$ (KRC3011) and CRP (88-7501-28) (all from Thermo Fisher Scientific, Inc.) were measured using ELISA kits. NO and
NOS were determined using the Total Nitric Oxide Assay and Nitric Oxide Synthase Assay kits, respectively.

Statistical analysis. The statistical analysis was performed using SPSS 19.0 software (IBM Corp., Armonk, NY, USA). The continuous variables are expressed as the mean \pm standard deviation. The comparisons between groups were analyzed using one-way analysis of variance. Multiple comparisons were analyzed using Dunnett's T3 post hoc test. The correlations between clinical data or serum factors and CIH were evaluated using Pearson's correlation coefficient. $\mathrm{P}<0.05$ was considered to indicate a statistically significant difference.

\section{Results}

Clinical data and hemodynamic analysis in Hakka patients. Comparisons between Hakka and non-Hakka patients with $\mathrm{CIH}$ combined with hypertension and healthy volunteers are presented in Table I and Fig. 1, including age, sex, body mass index (BMI), smoking and T2DM history, hemodynamic changes (SAP, DAP, MAP and HR), and serum markers (IL-6, TNF- $\alpha$, CRP, NO and NOS). The odds ratio and $r$ (correlation coefficient) values are representative of the entire cohort.

The patients with $\mathrm{CIH}$ combined with hypertension were older $(r=0.536)$, and more of them were males $(r=0.681)$. The patients exhibited increased BMI $(r=0.710)$ compared with the healthy volunteers, while the BMI of non-Hakka patients was significantly decreased compared with Hakka patients $(\mathrm{P}<0.05)$. More patients had a history of smoking $(\mathrm{r}=0.611)$ and T2DM ( $\mathrm{r}=0.692)$ compared with the healthy volunteers.

According to the results of the hemodynamic analysis, the patients exhibited increased SAP $(r=0.542)$, DAP $(r=0.602)$, MAP ( $\mathrm{r}=0.575)$ and HR $(\mathrm{r}=0.326)$ compared with the healthy volunteers. However, the SAP of Hakka patients was significantly decreased compared with that of non-Hakka patients $(\mathrm{P}<0.05)$.

The inflammatory factors, IL-6 ( $\mathrm{r}=0.787)$, TNF- $\alpha$ $(\mathrm{r}=0.619)$ and CRP $(\mathrm{r}=0.328)$, were increased in the patients compared with the healthy volunteers, while NO $(\mathrm{r}=-0.206)$ and NOS ( $r=-0.443)$ were decreased. The IL-6 and TNF- $\alpha$ levels were increased in non-Hakka patients compared with Hakka patients, while NO levels were significantly decreased $(\mathrm{P}<0.05)$.

Rat weight and hemodynamic alterations. The weight changes and comparisons between $\mathrm{CIH}$ and healthy rats are presented in Table II and Fig. 2A. Prior to the experiments, the average weight of the $\mathrm{CIH}$ rats was not significantly different from that of the control group. During the experiments, the average weight of the CIH and healthy rats increased gradually. However, the $\mathrm{CIH}$ rats exhibited decreased activity and appetite, resulting in the average $\mathrm{CIH}$ rat weight being significantly decreased compared with that of the healthy rats on the 7 th, 14th and 21st days $(\mathrm{P}<0.05)$.

The alterations in SAP, DAP, MAP and HR in CIH and healthy rats are presented in Table III and Fig. 2B-E. Prior to experiments, there was no significant difference in SAP, DAP, MAP or HR between CIH rats and healthy rats. During the experiments, the average SAP, DAP, MAP and HR of the CIH rats increased, gradually and significantly $(\mathrm{P}<0.05)$. Compared 
Table I. Clinical data, hemodynamic alterations, serum IL-6, TNF- $\alpha$, CRP, NO and NOS in Hakka and non-Hakka patients with CIH combined with hypertension, compared with healthy volunteers (mean \pm standard deviation).

\begin{tabular}{|c|c|c|c|c|c|c|}
\hline Variable & $\begin{array}{l}\text { Non-Hakka patients } \\
\qquad(\mathrm{n}=132)\end{array}$ & $\begin{array}{l}\text { Hakka patients } \\
\qquad(n=106)\end{array}$ & $\begin{array}{l}\text { Healthy volunteers } \\
\qquad(\mathrm{n}=156)\end{array}$ & OR & P-value & $\mathrm{r}$ \\
\hline Age, years & $47.93 \pm 2.75^{a}$ & $48.52 \pm 2.90^{\mathrm{a}}$ & $46.02 \pm 3.24$ & 1.73 & $<0.001$ & 0.536 \\
\hline \multicolumn{7}{|l|}{ Sex, n (\%) } \\
\hline Male & $86\left(65.15^{\mathrm{a}}\right)$ & $68,64.15^{\mathrm{a}}$ & $89(57.05)$ & 2.07 & $<0.001$ & 0.681 \\
\hline Female & $46\left(34.85^{\mathrm{a}}\right)$ & $38,35.85^{\mathrm{a}}$ & $67(42.95)$ & 0.85 & $<0.001$ & -0.326 \\
\hline $\mathrm{BMI}, \mathrm{kg} / \mathrm{cm}^{2}$ & $34.96 \pm 5.81^{\mathrm{a}}$ & $37.65 \pm 4.82^{\mathrm{a}, \mathrm{b}}$ & $26.04 \pm 3.97$ & 3.48 & $<0.001$ & 0.710 \\
\hline Smoking history, $\mathrm{n}(\%)$ & $32\left(24.24^{\mathrm{a}}\right)$ & $26,24.53^{\mathrm{a}}$ & $25(15.72)$ & 1.64 & 0.019 & 0.611 \\
\hline T2DM history, n (\%) & $22\left(16.67^{a}\right)$ & $15,14.15^{\mathrm{a}}$ & $8(5.13)$ & 4.83 & $<0.001$ & 0.692 \\
\hline $\mathrm{SAP}, \mathrm{mmHg}$ & $136.58 \pm 14.18^{\mathrm{a}}$ & $130.17 \pm 12.93^{\mathrm{a}, \mathrm{b}}$ & $106.24 \pm 10.37$ & 2.14 & $<0.001$ & 0.542 \\
\hline DAP, mmHg & $85.44 \pm 8.92^{\mathrm{a}}$ & $83.20 \pm 9.25^{\mathrm{a}}$ & $73.03 \pm 8.50$ & 1.83 & $<0.001$ & 0.602 \\
\hline $\mathrm{MAP}, \mathrm{mmHg}$ & $106.25 \pm 11.77^{\mathrm{a}}$ & $104.92 \pm 12.35^{\mathrm{a}}$ & $83.96 \pm 10.45$ & 1.95 & $<0.001$ & 0.575 \\
\hline $\mathrm{HR}, \mathrm{bpm}$ & $72.59 \pm 9.40^{\mathrm{a}}$ & $73.08 \pm 8.86^{\mathrm{a}}$ & $63.15 \pm 4.82$ & 1.79 & 0.016 & 0.326 \\
\hline $\mathrm{IL}-6, \mu \mathrm{g} / \mathrm{ml}$ & $24.13 \pm 4.22^{\mathrm{a}}$ & $20.65 \pm 3.82^{\mathrm{a}, \mathrm{b}}$ & $14.85 \pm 3.60$ & 2.37 & $<0.001$ & 0.787 \\
\hline TNF- $\alpha, p g / m l$ & $24.51 \pm 4.26^{\mathrm{a}}$ & $19.79 \pm 5.04^{\mathrm{a}, \mathrm{b}}$ & $8.67 \pm 1.33$ & 2.54 & $<0.001$ & 0.619 \\
\hline $\mathrm{CRP}, \mu \mathrm{g} / \mathrm{ml}$ & $3.94 \pm 0.85^{\mathrm{a}}$ & $3.70 \pm 0.73^{\mathrm{a}}$ & $1.56 \pm 0.38$ & 1.60 & $<0.001$ & 0.328 \\
\hline $\mathrm{NO}, \mu \mathrm{M}$ & $57.64 \pm 20.86^{\mathrm{a}}$ & $62.90 \pm 15.37^{\mathrm{a}, \mathrm{b}}$ & $78.94 \pm 16.55$ & 0.72 & $<0.001$ & -0.206 \\
\hline NOS, $\mathrm{U} / \mathrm{ml}$ & $37.28 \pm 6.50^{\mathrm{a}}$ & $38.83 \pm 7.45^{\mathrm{a}}$ & $40.36 \pm 5.42$ & 0.88 & 0.030 & -0.443 \\
\hline
\end{tabular}

${ }^{\mathrm{a}} \mathrm{P}<0.05$ vs. healthy volunteers; ${ }^{\mathrm{b}} \mathrm{P}<0.05$ vs. Hakka patients. $\mathrm{CIH}$, chronic intermittent hypoxia; OR, odds ratio; r, correlation coefficient; BMI, body mass index; T2DM, type 2 diabetes mellitus; SAP, systolic arterial pressure; DAP, diastolic arterial pressure; MAP, mean arterial pressure; HR, heart rate; IL-6, interleukin-6; TNF- $\alpha$, tumor necrosis factor- $\alpha$; CRP, C-reactive protein; NO, nitric oxide; NOS, nitric oxide synthase.

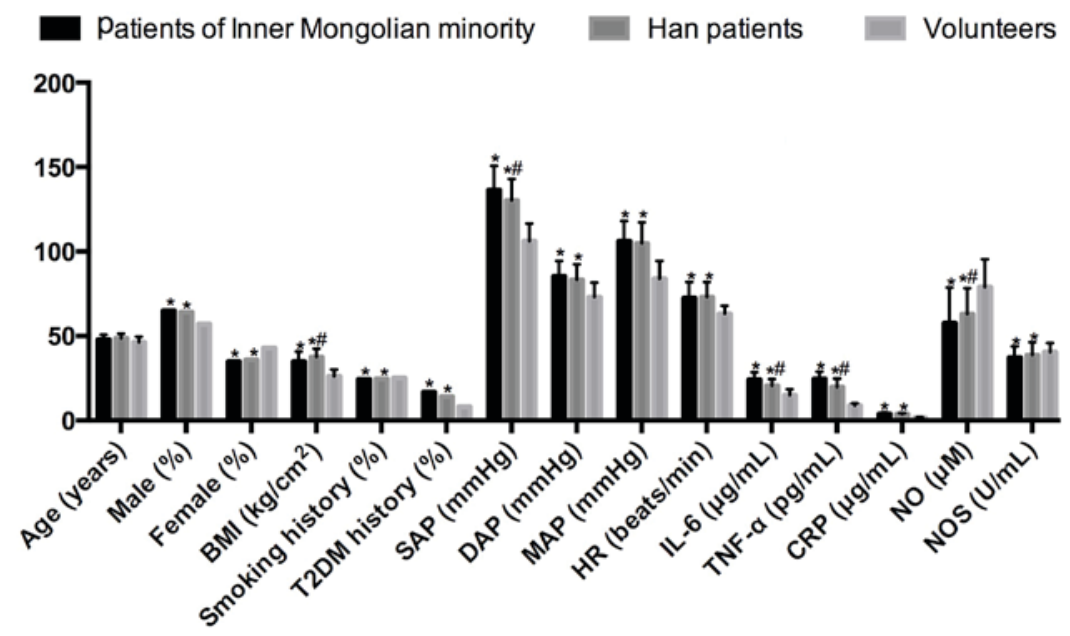

Figure 1. Comparisons of clinical data, hemodynamic changes, serum IL-6, TNF- $\alpha$, CRP, NO and NOS in non-Hakka and Hakka patients with CIH combined with hypertension, and healthy volunteers. ${ }^{*} \mathrm{P}<0.05$ vs. healthy volunteers; ${ }^{\#} \mathrm{P}<0.05$ vs. Hakka patients. $\mathrm{CIH}$, chronic intermittent hypoxia; OR, odds ratio; r, correlation coefficient; BMI, body mass index; T2DM, type 2 diabetes mellitus; SAP, systolic arterial pressure; DAP, diastolic arterial pressure; MAP, mean arterial pressure; HR, heart rate; IL-6, interleukin-6; TNF- $\alpha$, tumor necrosis factor- $\alpha$; CRP, C-reactive protein; NO, nitric oxide; NOS, nitric oxide synthase.

with the control, SAP, DAP, MAP and HR in the CIH rats on the 7 th, 14th and 21 st days were significantly increased $(\mathrm{P}<0.05)$.

Serum IL-6, TNF- $\alpha, C R P, N O$ and NOS alterations in rats. Serum IL-6, TNF- $\alpha$, CRP, NO and NOS in CIH and healthy rats are presented in Table IV and Fig. 3. Prior to experiments, there was no significant difference in serum IL-6, TNF- $\alpha$, $\mathrm{CRP}, \mathrm{NO}$ or NOS between $\mathrm{CIH}$ rats and healthy rats. During the experiments, serum IL-6, TNF- $\alpha$ and CRP in CIH rats increased, while NO and NOS decreased, gradually and significantly $(\mathrm{P}<0.05)$. Compared with the control, serum IL-6, TNF- $\alpha$ and CRP in CIH rats were significantly increased, while NO and NOS were significantly decreased, on the 7 th, 14 th and 21 st days $(\mathrm{P}<0.05)$.

Correlation between IL-6, TNF- $\alpha, C R P, N O$ and NOS, and $C I H$. The IL-6, TNF- $\alpha$, CRP, NO and NOS levels 
Table II. Weight changes in rats with or without $\mathrm{CIH}(\mathrm{n}=10$; mean \pm standard deviation).

During experiments, $g$

\begin{tabular}{lccccc}
\cline { 3 - 5 } Group & No. of rats & Prior to experiments, $\mathrm{g}$ & 7th day & 14th day & 21 st day \\
\hline CIH & 5 & $190.56 \pm 13.39$ & $215.51 \pm 12.38^{\mathrm{a}}$ & $235.40 \pm 11.25^{\mathrm{a}}$ & $257.93 \pm 13.43^{\mathrm{a}}$ \\
Control & 5 & $192.27 \pm 12.04$ & $229.07 \pm 13.58$ & $267.36 \pm 12.60$ & $298.83 \pm 12.81$
\end{tabular}

${ }^{\mathrm{a}} \mathrm{P}<0.05$ vs. control. $\mathrm{CIH}$, chronic intermittent hypoxia.

Table III. Hemodynamic alterations in rats with or without $\mathrm{CIH}(\mathrm{n}=10$; mean \pm standard deviation).

\begin{tabular}{llccccc}
\hline \multirow{2}{*}{$\begin{array}{l}\text { Hemodynamic } \\
\text { measurement }\end{array}$} & Group & No. of rats & $\begin{array}{c}\text { Prior to } \\
\text { experiments }\end{array}$ & & \multicolumn{3}{c}{ During experiments } \\
\cline { 5 - 7 } SAP, mmHg day & & 14 th day & 21 st day \\
& CIH & 5 & $105.36 \pm 7.93$ & $126.84 \pm 12.37^{\mathrm{a}, \mathrm{b}}$ & $138.60 \pm 10.54^{\mathrm{a}-\mathrm{c}}$ & $144.58 \pm 11.23^{\mathrm{a}-\mathrm{d}}$ \\
DAP, mmHg & Control & 5 & $102.05 \pm 8.60$ & $107.40 \pm 7.95$ & $110.32 \pm 10.77$ & $118.68 \pm 11.70$ \\
& CIH & 5 & $53.05 \pm 7.90$ & $75.44 \pm 10.28^{\mathrm{a}, \mathrm{b}}$ & $85.33 \pm 9.61^{\mathrm{a}-\mathrm{c}}$ & $90.37 \pm 9.55^{\mathrm{a}-\mathrm{d}}$ \\
MAP, mmHg & Control & 5 & $51.95 \pm 10.38$ & $55.62 \pm 12.09$ & $54.84 \pm 10.85$ & $56.07 \pm 11.63$ \\
& CIH & 5 & $69.59 \pm 8.70$ & $84.06 \pm 6.33^{\mathrm{a}, \mathrm{b}}$ & $103.52 \pm 7.47^{\mathrm{a}-\mathrm{c}}$ & $106.27 \pm 7.05^{\mathrm{a}-\mathrm{d}}$ \\
HR, bpm & Control & 5 & $70.22 \pm 9.83$ & $73.52 \pm 10.24$ & $78.92 \pm 8.66$ & $77.35 \pm 10.41$ \\
& CIH & 5 & $290.33 \pm 34.51$ & $319.45 \pm 48.52^{\mathrm{a}, \mathrm{b}}$ & $327.66 \pm 43.57^{\mathrm{a}-\mathrm{c}}$ & $336.58 \pm 46.30^{\mathrm{a}-\mathrm{d}}$ \\
& Control & 5 & $288.65 \pm 35.40$ & $291.05 \pm 36.87$ & $295.60 \pm 39.12$ & $297.31 \pm 37.05$ \\
\hline
\end{tabular}

${ }^{\mathrm{a}} \mathrm{P}<0.05$ vs. control; ${ }^{\mathrm{b}} \mathrm{P}<0.05$ vs. $\mathrm{CIH}$ prior to experiments; ${ }^{\mathrm{C}} \mathrm{P}<0.05$ vs. $\mathrm{CIH} 7$ th day; ${ }^{\mathrm{d}} \mathrm{P}<0.05$ vs. CIH 14 th day. CIH, chronic intermittent hypoxia; SAP, systolic arterial pressure; DAP, diastolic arterial pressure; MAP, mean arterial pressure; HR, heart rate.

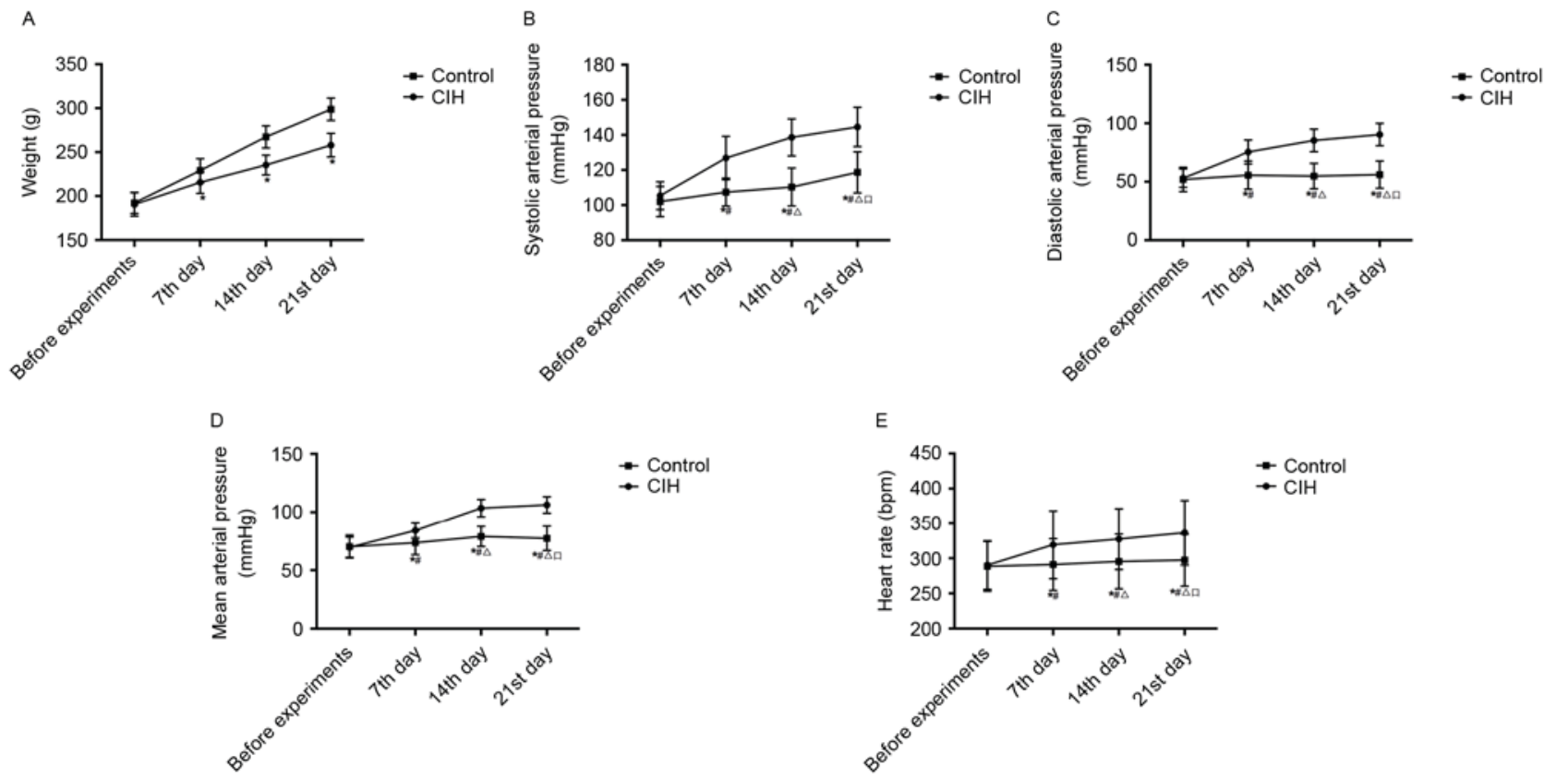

Figure 2. Comparison of alterations in (A) weight, (B) SAP, (C) DAP, (D) MAP and (E) HR in rats with or without CIH prior to experiments and at the 7th, 14th and 21 st day during experiments. ${ }^{*} \mathrm{P}<0.05$ vs. control; ${ }^{*} \mathrm{P}<0.05$ vs. CIH before experiments; ${ }^{\wedge} \mathrm{P}<0.05$ vs. CIH 7 th day; ${ }^{\circ} \mathrm{P}<0.05$ vs. CIH 14 th day. CIH, chronic intermittent hypoxia-hypertension; SAP, systolic arterial pressure; DAP, diastolic arterial pressure; MAP, mean arterial pressure; HR, heart rate.

were correlated with CIH, including SAP, DAP, MAP and HR, which are presented as the correlation coefficient (r) in Table V. IL-6 was positively correlated with SAP $(\mathrm{r}=0.572)$, DAP $(r=0.439)$, MAP $(r=0.640)$ and HR $(r=0.530)$, 
Table IV. Serum IL-6, TNF- $\alpha$, CRP, NO and NOS alterations in rats with or without CIH ( $\mathrm{n}=10$; mean \pm standard deviation).

\begin{tabular}{|c|c|c|c|c|c|c|}
\hline \multirow[b]{2}{*}{ Variable } & \multirow[b]{2}{*}{ Groups } & \multirow[b]{2}{*}{ No. of rats } & \multirow{2}{*}{$\begin{array}{c}\text { Prior to } \\
\text { experiments }\end{array}$} & \multicolumn{3}{|c|}{ During experiments } \\
\hline & & & & 7th day & 14th day & 21 st day \\
\hline \multirow{2}{*}{ IL-6, ng/ml } & $\mathrm{CIH}$ & 5 & $169.75 \pm 13.62$ & $180.36 \pm 11.70^{\mathrm{a}, \mathrm{b}}$ & $188.54 \pm 14.16^{\mathrm{a}-\mathrm{c}}$ & $193.27 \pm 13.58^{\mathrm{a}-\mathrm{d}}$ \\
\hline & Control & 5 & $167.44 \pm 12.79$ & $169.38 \pm 13.83$ & $168.07 \pm 11.25$ & $170.62 \pm 13.46$ \\
\hline \multirow[t]{2}{*}{ TNF- $\alpha, p g / m l$} & $\mathrm{CIH}$ & 5 & $8.66 \pm 1.49$ & $16.02 \pm 3.58^{\mathrm{a}, \mathrm{b}}$ & $18.34 \pm 3.75^{\mathrm{a}-\mathrm{c}}$ & $22.40 \pm 4.07^{\mathrm{a}-\mathrm{d}}$ \\
\hline & Control & 5 & $8.74 \pm 1.69$ & $8.80 \pm 2.05$ & $8.93 \pm 1.37$ & $8.85 \pm 1.08$ \\
\hline \multirow[t]{2}{*}{$\mathrm{CRP}, \mu \mathrm{g} / \mathrm{ml}$} & $\mathrm{CIH}$ & 5 & $1.56 \pm 0.32$ & $2.84 \pm 0.97^{\mathrm{a}, \mathrm{b}}$ & $3.32 \pm 0.85^{\mathrm{a}-\mathrm{c}}$ & $3.87 \pm 0.63^{\mathrm{a}-\mathrm{d}}$ \\
\hline & Control & 5 & $1.58 \pm 0.50$ & $1.63 \pm 0.44$ & $1.62 \pm 0.81$ & $1.60 \pm 0.64$ \\
\hline \multirow[t]{2}{*}{$\mathrm{NO}, \mu \mathrm{M}$} & $\mathrm{CIH}$ & 5 & $47.92 \pm 10.36$ & $40.73 \pm 9.18^{\mathrm{a}, \mathrm{b}}$ & $32.67 \pm 9.22^{\mathrm{a}-\mathrm{c}}$ & $22.03 \pm 7.71^{\mathrm{a}-\mathrm{d}}$ \\
\hline & Control & 5 & $48.17 \pm 9.50$ & $49.14 \pm 8.72$ & $48.85 \pm 9.69$ & $48.36 \pm 8.14$ \\
\hline \multirow[t]{2}{*}{ NOS, U/ml } & $\mathrm{CIH}$ & 5 & $23.65 \pm 4.06$ & $19.28 \pm 3.41^{\mathrm{a}, \mathrm{b}}$ & $17.16 \pm 4.04^{\mathrm{a}-\mathrm{c}}$ & $13.97 \pm 3.15^{\mathrm{a}-\mathrm{d}}$ \\
\hline & Control & 5 & $24.37 \pm 3.80$ & $25.62 \pm 5.86$ & $26.71 \pm 4.51$ & $24.98 \pm 4.70$ \\
\hline
\end{tabular}

${ }^{a} \mathrm{P}<0.05$ vs. control; ${ }^{\mathrm{b}} \mathrm{P}<0.05$ vs. $\mathrm{CIH}$ prior to experiments; ${ }^{\mathrm{c}} \mathrm{P}<0.05$ vs. $\mathrm{CIH} 7$ th day; ${ }^{\mathrm{d}} \mathrm{P}<0.05$ vs. $\mathrm{CIH} 14$ th day. $\mathrm{CIH}$, chronic intermittent hypoxia-hypertension; IL-6, interleukin-6; TNF- $\alpha$, tumor necrosis factor- $\alpha$; CRP, C-reactive protein; NO, nitric oxide; NOS, nitric oxide synthase.
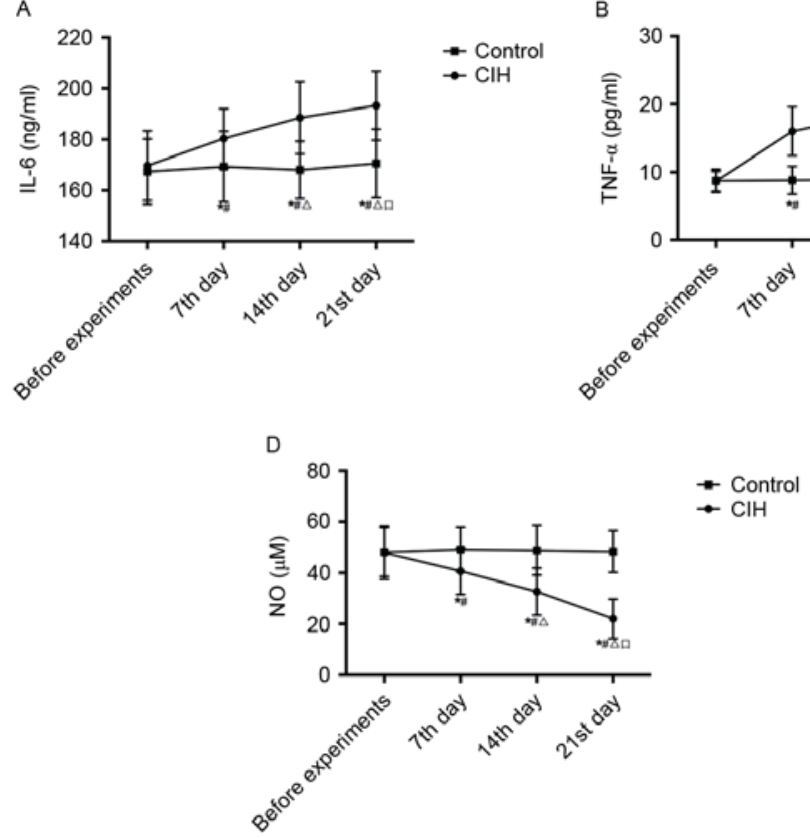

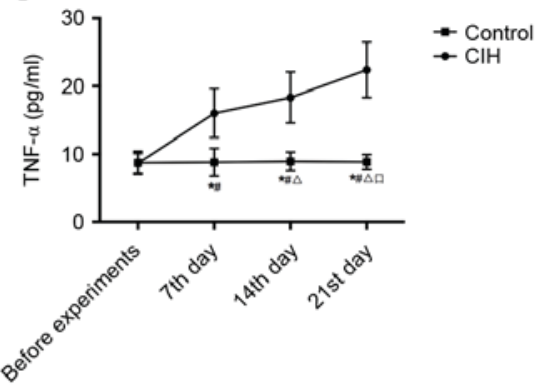

$\mathrm{E}$
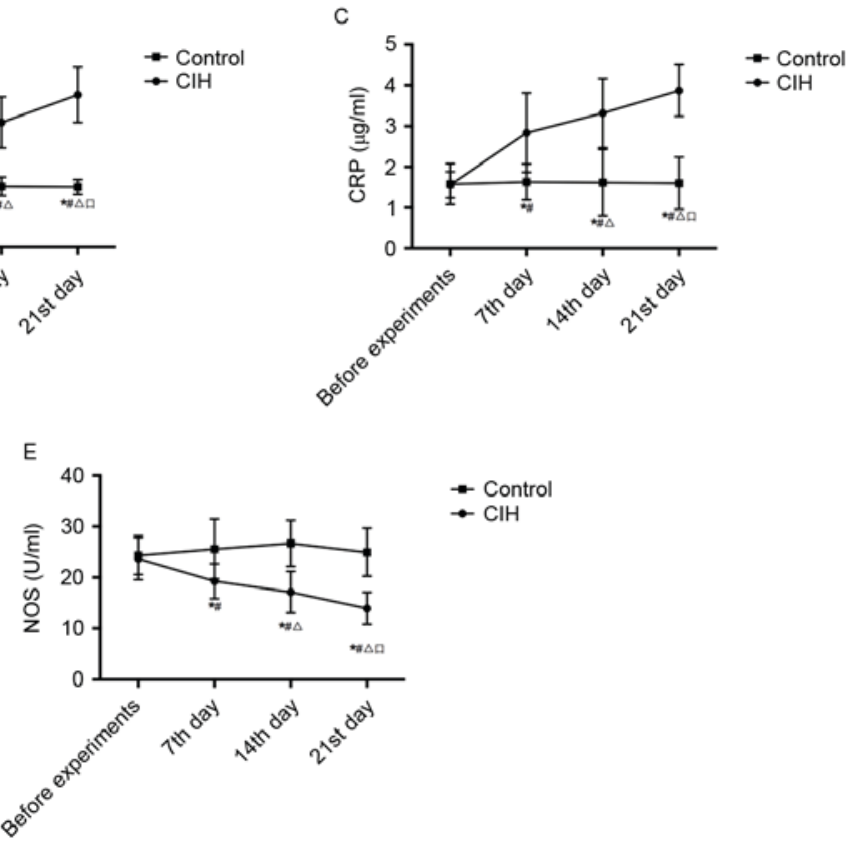

Figure 3. Comparison of alterations in (A) IL-6, (B) TNF- $\alpha$, (C) CRP, (D) NO and (E) NOS in rats with or without CIH prior to experiments and at the 7th, 14th and 21 st day during experiments. ${ }^{*} \mathrm{P}<0.05$ vs. control; ${ }^{*} \mathrm{P}<0.05$ vs. $\mathrm{CIH}$ before experiments; ${ }^{\Delta} \mathrm{P}<0.05$ vs. CIH 7 th day; ${ }^{\square} \mathrm{P}<0.05$ vs. $\mathrm{CIH} 14$ th day. CIH, chronic intermittent hypoxia-hypertension; IL-6, interleukin-6; TNF- $\alpha$, tumor necrosis factor- $\alpha$; CRP, C-reactive protein; NO, nitric oxide; NOS, nitric oxide synthase.

in addition to TNF- $\alpha$ with SAP ( $\mathrm{r}=0.673)$, DAP $(\mathrm{r}=0.519)$, MAP $(r=0.436)$ and HR $(r=0.448)$, and CRP with SAP $(r=0.397)$, DAP $(r=0.418)$, MAP $(r=0.607)$ and HR $(\mathrm{r}=0.528)$; NO and NOS were negatively correlated with SAP ( $r=-0.568$ and $r=-0.473)$, DAP $(r=-0.372$ and $r=-0.460)$, MAP ( $r=-0.406$ and $r=-0.524)$ and HR ( $r=-0.630$ and $\mathrm{r}=-0.581)$.

Apoptosis rate, IL-6,TNF- $\alpha, C R P, N O$ and iNOS in rat lymphocytes. Apoptosis rate, IL- $6, \mathrm{TNF}-\alpha, \mathrm{CRP}, \mathrm{NO}$ and iNOS in $\mathrm{CIH}$ and control rats are presented in Table VI and Figs. 4 and 5.
The apoptosis rat in $\mathrm{CIH}$ rats was significantly decreased compared with healthy rats $(\mathrm{P}<0.05$; Fig. 4). The levels of IL-6, TNF- $\alpha$, CRP, NO and iNOS were significantly increased in $\mathrm{CIH}$ rats compared with healthy rats $(\mathrm{P}<0.05$; Fig. 5).

IL-6,TNF- $\alpha, C R P, N O$, , NOS and iNOS in rat endotheliocytes. IL-6, TNF- $\alpha$, CRP, NO, eNOS and iNOS in rat endotheliocytes prior to and following $\mathrm{CIH}$ induction are presented in Table VII and Fig. 6. During the $3 \mathrm{~h}$ of CIH induction, IL-6, TNF- $\alpha, \mathrm{CRP}$ and iNOS in rat endotheliocytes increased, while $\mathrm{NO}$ and eNOS decreased, gradually and significantly $(\mathrm{P}<0.05)$. 
Table V. Correlation coefficients of IL-6, TNF- $\alpha$, CRP, NO and NOS with SAP, DAP, MAP and HR in CIH rats.

Correlation coefficient (r)

\begin{tabular}{lcccc}
\cline { 2 - 5 } Variable & SAP & DAP & MAP & HR \\
\hline IL-6 & $0.572^{\mathrm{b}}$ & $0.439^{\mathrm{a}}$ & $0.640^{\mathrm{b}}$ & $0.530^{\mathrm{b}}$ \\
TNF- $\alpha$ & $0.673^{\mathrm{b}}$ & $0.519^{\mathrm{b}}$ & $0.436^{\mathrm{a}}$ & $0.448^{\mathrm{a}}$ \\
CRP & $0.397^{\mathrm{a}}$ & $0.418^{\mathrm{a}}$ & $0.607^{\mathrm{b}}$ & $0.528^{\mathrm{b}}$ \\
NO & $-0.568^{\mathrm{b}}$ & $-0.372^{\mathrm{a}}$ & $-0.406^{\mathrm{a}}$ & $-0.630^{\mathrm{b}}$ \\
NOS & $-0.473^{\mathrm{a}}$ & $-0.460^{\mathrm{a}}$ & $-0.524^{\mathrm{b}}$ & $-0.581^{\mathrm{b}}$ \\
\hline
\end{tabular}

${ }^{\mathrm{a}} \mathrm{P}<0.05$; ${ }^{\mathrm{b}} \mathrm{P}<0.01$. $\mathrm{CIH}$, chronic intermittent hypoxia-hypertension; IL-6, interleukin-6; TNF- $\alpha$, tumor necrosis factor- $\alpha$; CRP, C-reactive protein; NO, nitric oxide; NOS, nitric oxide synthase; SAP, systolic arterial pressure; DAP, diastolic arterial pressure; MAP, mean arterial pressure; HR, heart rate.

Table VI. Apoptosis, IL-6, TNF- $\alpha$, CRP, NO and iNOS in rat lymphocytes in rats with or without $\mathrm{CIH}$.

\begin{tabular}{lrr}
\hline Variable & \multicolumn{1}{c}{ CIH } & \multicolumn{1}{c}{ Control } \\
\hline Apoptosis rate, $\%$ & $18.59 \pm 2.83^{\mathrm{a}}$ & $29.46 \pm 1.70$ \\
IL-6, ng/ml & $2.84 \pm 0.15^{\mathrm{a}}$ & $0.77 \pm 0.11$ \\
TNF- $\alpha, \mathrm{pg} / \mathrm{ml}$ & $1.73 \pm 0.08^{\mathrm{a}}$ & $0.38 \pm 0.06$ \\
$\mathrm{CRP}, \mu \mathrm{g} / \mathrm{ml}$ & $1.95 \pm 0.07^{\mathrm{a}}$ & $0.65 \pm 0.07$ \\
$\mathrm{NO}, \mu \mathrm{M}$ & $4.04 \pm 0.21^{\mathrm{a}}$ & $2.38 \pm 0.14$ \\
iNOS, U/ml & $0.73 \pm 0.05^{\mathrm{a}}$ & $0.10 \pm 0.03$ \\
\hline
\end{tabular}

${ }^{a} \mathrm{P}<0.05$ vs. control. $\mathrm{CIH}$, chronic intermittent hypoxia; IL-6, interleukin-6; TNF- $\alpha$, tumor necrosis factor- $\alpha$; CRP, C-reactive protein; NO, nitric oxide; iNOS, inducible nitric oxide synthase.

Compared with the control, IL-6, TNF- $\alpha$, CRP and iNOS in rat endotheliocytes with $\mathrm{CIH}$ induction were significantly increased, while NO and eNOS were decreased, at 1,2 and $3 \mathrm{~h}(\mathrm{P}<0.05)$.

IL-6,TNF- $\alpha, C R P, N O$ and NOS in co-culturing supernatant of lymphocytes and endotheliocytes. IL- 6 , TNF- $\alpha, \mathrm{CRP}$, $\mathrm{NO}$ and NOS levels in the supernatant of co-cultured rat lymphocytes and endotheliocytes are presented in Table VIII and Fig. 7. Compared with the CON-L+CON-E group, the IL-6, TNF- $\alpha$ and CRP levels in the CIH-L+CIH-E, $\mathrm{CIH}-\mathrm{L}+\mathrm{CON}-\mathrm{E}$ and $\mathrm{CON}-\mathrm{L}+\mathrm{CIH}-\mathrm{E}$ groups increased, and were significantly increased in the CIH-L+CIH-E compared with the CIH-L+CON-E and CON-L+CIH-E groups $(\mathrm{P}<0.05)$. The total NO and NOS in the CON-L+CON-E group was decreased compared with the CIH-L+CIH-E, $\mathrm{CIH}-\mathrm{L}+\mathrm{CON}-\mathrm{E}$ and CON-L+CIH-E groups $(\mathrm{P}<0.05)$.

\section{Discussion}

Comparison between Hakka CIH patients and non-Hakka $\mathrm{CIH}$ patients. According to the analysis of hemodynamic alterations, the patients with $\mathrm{CIH}$ exhibited hypertension. From analysis of the clinical data in the patients with CIH combined with hypertension, it was observed that older people exhibited an increased incidence, as did males. The results of the analysis of BMI and T2DM history indicated that obesity was associated with an increased incidence of $\mathrm{CIH}$ combined with hypertension. However, the BMI of the non-Hakka patients was decreased, which indicated that the Hakka patients with increased BMI may be at increased risk of $\mathrm{CIH}$ combined with hypertension. Obesity results in excessive fat around the neck, a softened airway and relative macroglossia, resulting in snoring (23). It was hypothesized that certain factors may protect the Hakka people, even with their higher average BMI, from obesity. In addition, individuals who smoke may be at an increased risk of $\mathrm{CIH}$ combined with hypertension, demonstrating that smoking is a risk factor for $\mathrm{CIH}$.

Through hemodynamic analysis, it was observed that patients with CIH exhibited increased SAP, DAP, MAP and HR compared with healthy people. However, the non-Hakka patients exhibited increased SAP compared with Hakka patients, suggesting that the Hakka people may have a decreased SAP in CIH combined with hypertension, or that there are other factors influencing their SAP.

Through the comparisons of serum markers, it was demonstrated that patients with $\mathrm{CIH}$ combined with hypertension exhibited increased serum IL-6, TNF- $\alpha$ and CRP levels, and decreased NO and NOS levels, compared with healthy volunteers. When comparing between different patients, the IL-6 and TNF- $\alpha$ levels were increased in non-Hakka patients compared with Hakka patients, while the NO level was decreased. The results of the present study indicated decreased inflammation in Hakka patients with CIH combined with hypertension. Therefore, there may be factors which protect the Hakka people from inflammation.

It was previously demonstrated that $\mathrm{CIH}$ may stimulate neuromodulatory adaptive changes, influencing the control of breathing, the autonomic nervous system and the cardiovascular system (24). CIH may present with interstitial lung disease (25) and sleep-disordered breathing (26). In addition, $\mathrm{CIH}$ has been observed to occur in Hakka patients with hepatopulmonary syndromes (27). Increasing attention has been paid to the association between $\mathrm{CIH}$ and breathing disorders associated with sleep, including obstructive sleep apnea (OSA) (28). OSA is associated with a number of cardiovascular conditions, and one of the closest associations was observed with systemic hypertension (29). The majority of patients with OSA exhibit sleep disruption, which may induce sympathetic disorders of nerve activity and blood pressure (30). The results of the present study indicated the differences between patients with $\mathrm{CIH}$ in different populations. These data may provide novel insights into the diagnosis, treatment and prevention of $\mathrm{CIH}$, particularly in different populations.

CIH models. In previous studies, the important role of hypoxia in promoting an increase in blood pressure was investigated in humans (31) or by establishing animal models (32). There are a number of advantages to using animal models, including the fact that a single component may be evaluated accurately in a homogeneous population (33). A CIH model in rats was established in the present study. By detecting the SAP, DAP, MAP and HR 

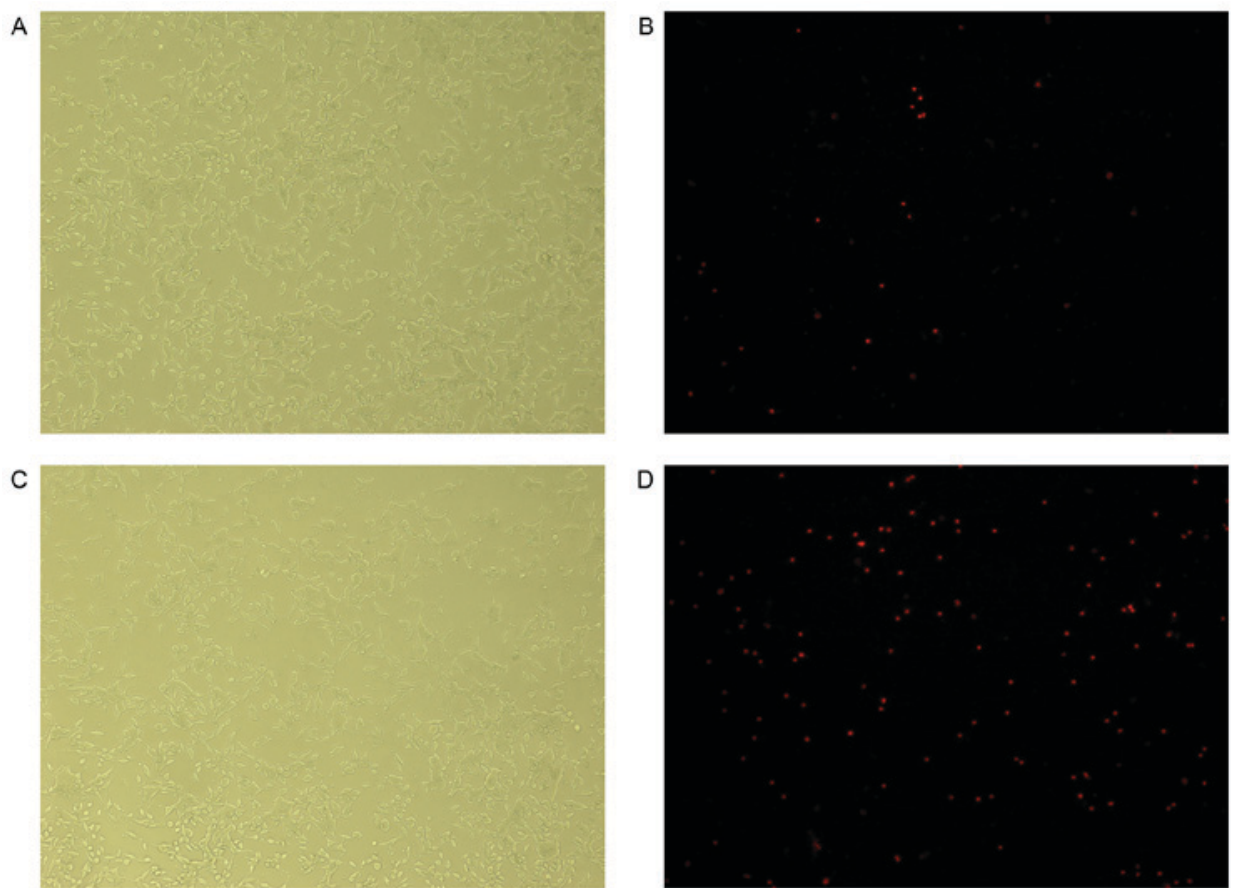

$E$

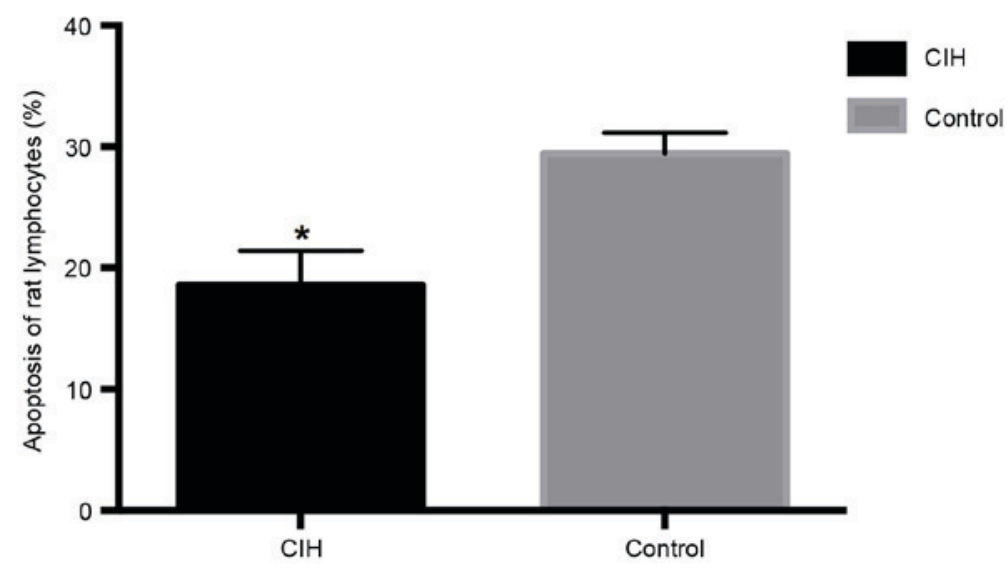

Figure 4. Apoptosis of rat lymphocytes in the $\mathrm{CIH}$ or control groups. (A) Rat lymphocytes in the $\mathrm{CIH}$ group (original magnification, $\mathrm{x} 100$ ). (B) Apoptosis of rat lymphocytes in the CIH group (original magnification, x100; $535 \mathrm{~nm}$ ); (C) Rat lymphocytes in the control group (original magnification, x100). (D) Apoptosis of rat lymphocytes in the control group (original magnification, $\mathrm{x} 100 ; 535 \mathrm{~nm}$ ). (E) Comparison between apoptosis of rat lymphocytes. "P<0.05 vs. control. $\mathrm{CIH}$, chronic intermittent hypoxia.

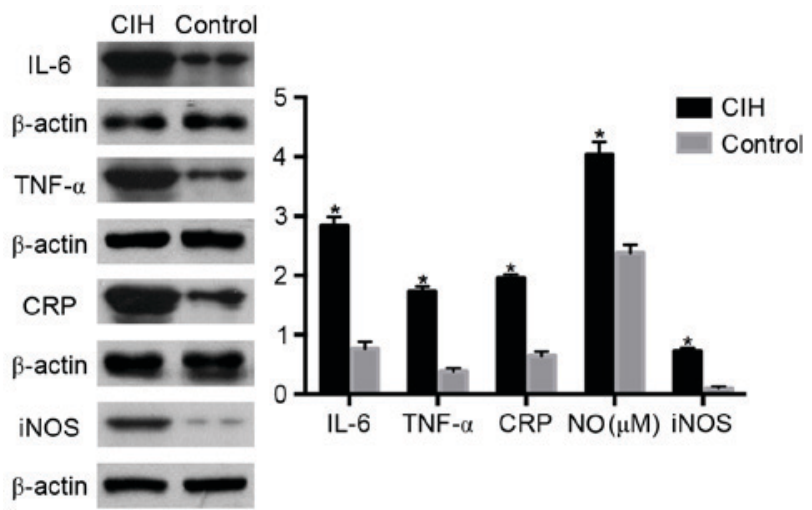

Figure 5. Alterations in IL-6, TNF- $\alpha, \mathrm{CRP}, \mathrm{NO}$ and iNOS in rat lymphocytes in the $\mathrm{CIH}$ or control groups, assessed by western blotting analysis. ${ }^{*} \mathrm{P}<0.05$ vs. control. $\mathrm{CIH}$, chronic intermittent hypoxia; IL-6, interleukin-6; TNF- $\alpha$, tumor necrosis factor- $\alpha$; CRP, C-reactive protein; NO, nitric oxide; iNOS, inducible nitric oxide synthase. at different timepoints, it was successfully confirmed that $\mathrm{CIH}$ was able to induce hypertension. The SAP, DAP, MAP and HR increased gradually, which indicated that $\mathrm{CIH}$ may promote an increase in blood pressure in rats in a time-dependent manner.

The $\mathrm{CIH}$ rats were less active and exhibited a decreased appetite, resulting in decreased weight gain compared with healthy rats. OSA was not detected in CIH rats in the present study; it was hypothesized that there were sleep-related disorders in the $\mathrm{CIH}$ rats, although this requires further investigation.

In a previous study (34), it was demonstrated that OSA may cause repetitive episodes of airway occlusion with hypoxia, hypercapnia, and alterations in intrathoracic pressure, which may lead to diverse autonomic, humoral, neurohumoral and hemodynamic responses. Indeed, serum IL-6, TNF- $\alpha$ and CRP have been observed to be elevated in patients with OSA $(35,36)$, although there is little evidence to identify a direct association between serum IL-6, TNF- $\alpha$ and CRP, and 
Table VII. IL-6, TNF- $\alpha$, CRP, NO, eNOS and iNOS in rat endotheliocytes prior to and following CIH induction.

$\mathrm{CIH}$ induction time

\begin{tabular}{llllll} 
Factor & Groups & \multicolumn{1}{c}{$0 \mathrm{~h}$} & $1 \mathrm{~h}$ & $2 \mathrm{~h}$ & \multicolumn{1}{c}{$3 \mathrm{~h}$} \\
\hline $\mathrm{IL}-6, \mathrm{ng} / \mathrm{ml}$ & CIH & $0.72 \pm 0.08$ & $1.24 \pm 0.09^{\mathrm{a}}$ & $1.85 \pm 0.05^{\mathrm{a}, \mathrm{b}}$ & $2.34 \pm 0.05^{\mathrm{a}-\mathrm{c}}$ \\
& Control & $0.65 \pm 0.04$ & $0.79 \pm 0.08$ & $0.84 \pm 0.04$ & $0.95 \pm 0.02$ \\
$\mathrm{TNF}-\alpha, \mathrm{pg} / \mathrm{ml}$ & CIH & $0.83 \pm 0.07$ & $1.16 \pm 0.06^{\mathrm{a}, \mathrm{b}}$ & $2.05 \pm 0.08^{\mathrm{a}-\mathrm{c}}$ & $2.18 \pm 0.06^{\mathrm{a}-\mathrm{c}}$ \\
& Control & $0.62 \pm 0.03$ & $0.68 \pm 0.09$ & $0.54 \pm 0.05$ & $0.86 \pm 0.06$ \\
$\mathrm{CRP}, \mu \mathrm{g} / \mathrm{ml}$ & CIH & $0.79 \pm 0.03$ & $0.95 \pm 0.08^{\mathrm{a}, \mathrm{b}}$ & $1.04 \pm 0.07^{\mathrm{a}, \mathrm{b}}$ & $1.27 \pm 0.05^{\mathrm{a}-\mathrm{d}}$ \\
& Control & $0.82 \pm 0.05$ & $0.80 \pm 0.08$ & $0.72 \pm 0.05$ & $0.66 \pm 0.03$ \\
$\mathrm{NO}, \mu \mathrm{M}$ & CIH & $3.54 \pm 0.26$ & $2.88 \pm 0.14^{\mathrm{a}, \mathrm{b}}$ & $1.60 \pm 0.22^{\mathrm{a}-\mathrm{c}}$ & $1.04 \pm 0.19^{\mathrm{a}-\mathrm{d}}$ \\
& Control & $3.92 \pm 0.33$ & $4.25 \pm 0.27$ & $3.51 \pm 0.22$ & $4.07 \pm 0.30$ \\
$\mathrm{eNOS}, \mathrm{U} / \mathrm{ml}$ & CIH & $2.38 \pm 0.09$ & $0.82 \pm 0.04^{\mathrm{a}, \mathrm{b}}$ & $0.46 \pm 0.05^{\mathrm{a}-\mathrm{c}}$ & $0.30 \pm 0.03^{\mathrm{a}-\mathrm{d}}$ \\
& Control & $2.06 \pm 0.05$ & $1.73 \pm 0.08$ & $1.80 \pm 0.06$ & $1.62 \pm 0.04$ \\
iNOS, U/ml & CIH & $0.18 \pm 0.05$ & $0.26 \pm 0.07^{\mathrm{a}}$ & $0.38 \pm 0.04^{\mathrm{a}, \mathrm{b}}$ & $0.40 \pm 0.05^{\mathrm{a}, \mathrm{b}}$ \\
& Control & $0.09 \pm 0.01$ & $0.07 \pm 0.03$ & $0.11 \pm 0.02$ & $0.08 \pm 0.02$
\end{tabular}

${ }^{\mathrm{a}} \mathrm{P}<0.05$ vs. control; ${ }^{b} \mathrm{P}<0.05$ vs. $\mathrm{CIH}-0 \mathrm{~h}$; ${ }^{\mathrm{C}} \mathrm{P}<0.05$ vs. $\mathrm{CIH}-1 \mathrm{~h}$; ${ }^{\mathrm{d}} \mathrm{P}<0.05$ vs. $\mathrm{CIH}-2 \mathrm{~h}$. $\mathrm{CIH}$, chronic intermittent hypoxia; IL-6, interleukin-6; TNF- $\alpha$, tumor necrosis factor- $\alpha$; CRP, C-reactive protein; NO, nitric oxide; eNOS, endothelial nitric oxide synthase; iNOS, inducible nitric oxide synthase.

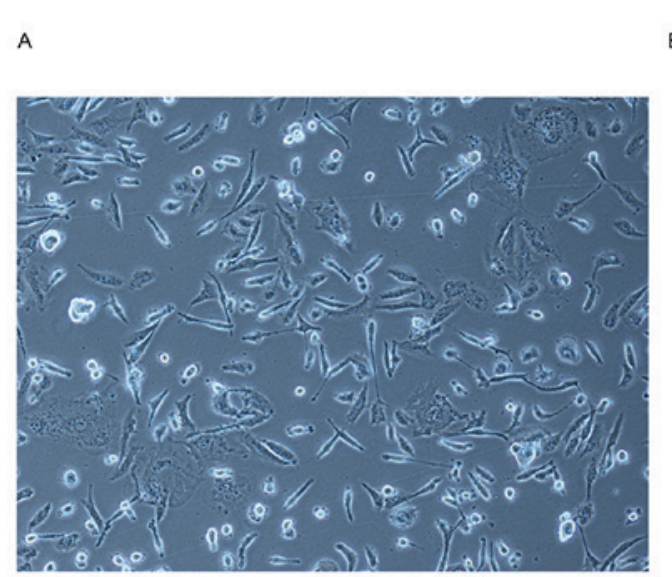

C
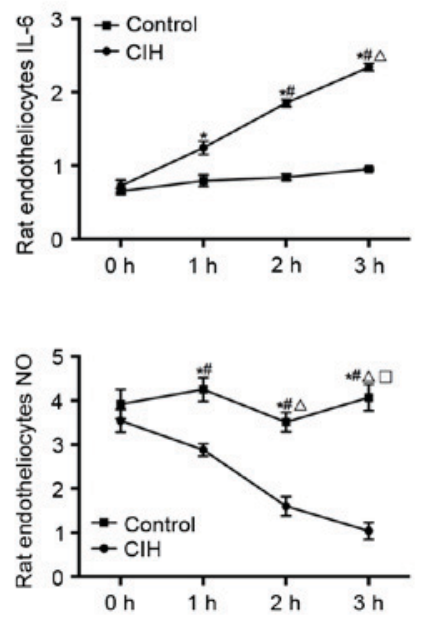

G
B

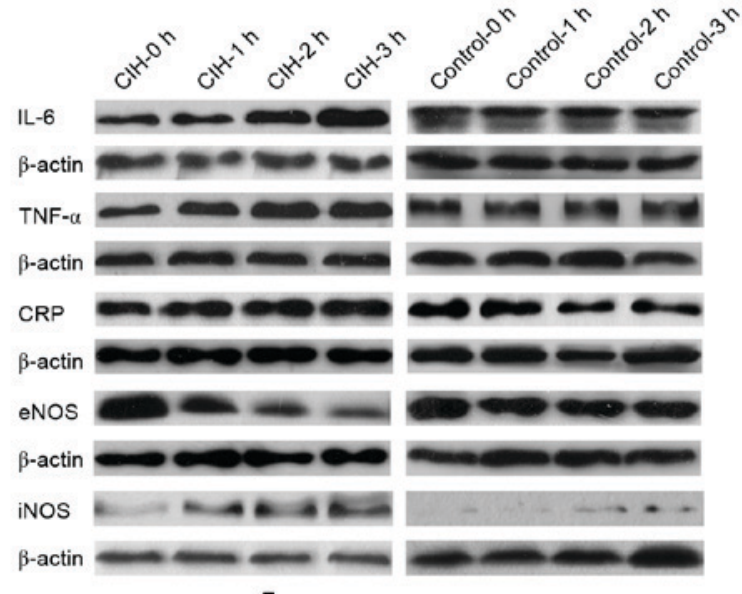

$E$
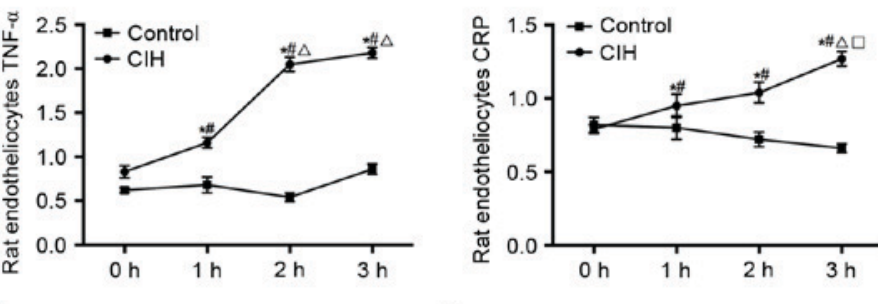

H

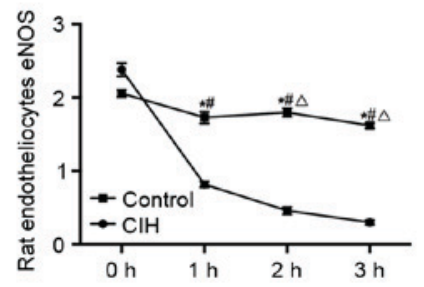

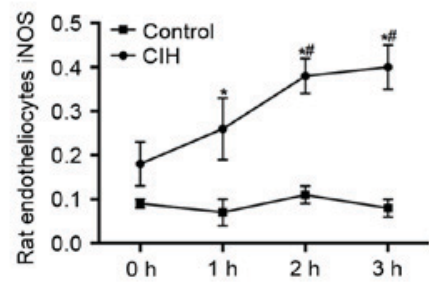

Figure 6. Alterations in IL-6, TNF- $\alpha, \mathrm{CRP}, \mathrm{NO}$, eNOS and iNOS in rat endotheliocytes prior to and following CIH induction. (A) Rat endotheliocytes (original magnification, x100). (B) Protein levels of IL-6, TNF- $\alpha$, CRP, eNOS and iNOS in rat endotheliocytes prior to and following CIH induction, ssessed by western blotting. (C) Rat endotheliocytes IL-6. (D) Rat endotheliocytes TNF- $\alpha$. (E) Rat endotheliocytes CRP. (F) Rat endotheliocytes NO. (G) Rat endotheliocytes eNOS. (H) Rat endotheliocytes iNOS. ${ }^{*} \mathrm{P}<0.05$ vs. control; ${ }^{\#} \mathrm{P}<0.05$ vs. CIH-0 h; ${ }^{\Delta} \mathrm{P}<0.05$ vs. CIH-1; ${ }^{\square} \mathrm{P}<0.05$ vs. CIH-2 h. CIH, chronic intermittent hypoxia; IL-6, interleukin-6; TNF- $\alpha$, tumor necrosis factor- $\alpha$; CRP, C-reactive protein; NO, nitric oxide; eNOS, endothelial nitric oxide synthase; iNOS, inducible nitric oxide synthase. 
Table VIII. IL-6, TNF- $\alpha$, CRP, NO and NOS in the co-culture supernatant of rat lymphocytes and endotheliocytes.

\begin{tabular}{lccrr}
\hline Variable & CIH-L+CIH-E & CIH-L+CON-E & CON-L+CIH-E & CON-L+CON-E \\
\hline IL-6, pg/ml & $187.94 \pm 20.36^{\mathrm{a}-\mathrm{c}}$ & $154.08 \pm 17.93^{\mathrm{a}}$ & $125.93 \pm 13.20^{\mathrm{a}}$ & $86.51 \pm 10.68$ \\
$\mathrm{TNF}-\alpha, \mathrm{pg} / \mathrm{ml}$ & $180.77 \pm 17.35^{\mathrm{a}-\mathrm{c}}$ & $146.38 \pm 15.90^{\mathrm{a}}$ & $127.37 \pm 14.62^{\mathrm{a}}$ & $102.64 \pm 11.86$ \\
$\mathrm{CRP}, \mathrm{pg} / \mathrm{ml}$ & $253.35 \pm 25.89^{\mathrm{a}-\mathrm{c}}$ & $190.28 \pm 16.72^{\mathrm{a}}$ & $158.44 \pm 15.20^{\mathrm{a}}$ & $108.95 \pm 9.54$ \\
$\mathrm{NO}, \mu \mathrm{M}$ & $3.06 \pm 0.25^{\mathrm{a}}$ & $4.27 \pm 0.63^{\mathrm{a}}$ & $3.84 \pm 0.41^{\mathrm{a}}$ & $6.06 \pm 0.52$ \\
NOS, $\mathrm{U} / \mathrm{ml}$ & $1.94 \pm 0.07^{\mathrm{a}}$ & $2.84 \pm 0.33^{\mathrm{a}}$ & $2.50 \pm 0.19^{\mathrm{a}}$ & $4.35 \pm 0.26$ \\
\hline
\end{tabular}

${ }^{a} \mathrm{P}<0.05$ vs. CON-L+CON-E group; ${ }^{\mathrm{b}} \mathrm{P}<0.05$ vs. CIH-L+CON-E group; ${ }^{\mathrm{P}}<0.05$ vs. CON-L+CIH-E group. CIH, chronic intermittent hypoxia; IL-6, interleukin-6; TNF- $\alpha$, tumor necrosis factor- $\alpha$; CRP, C-reactive protein; NO, nitric oxide; NOS, nitric oxide synthase; CON, control; L, lymphocytes; E, endotheliocytes.
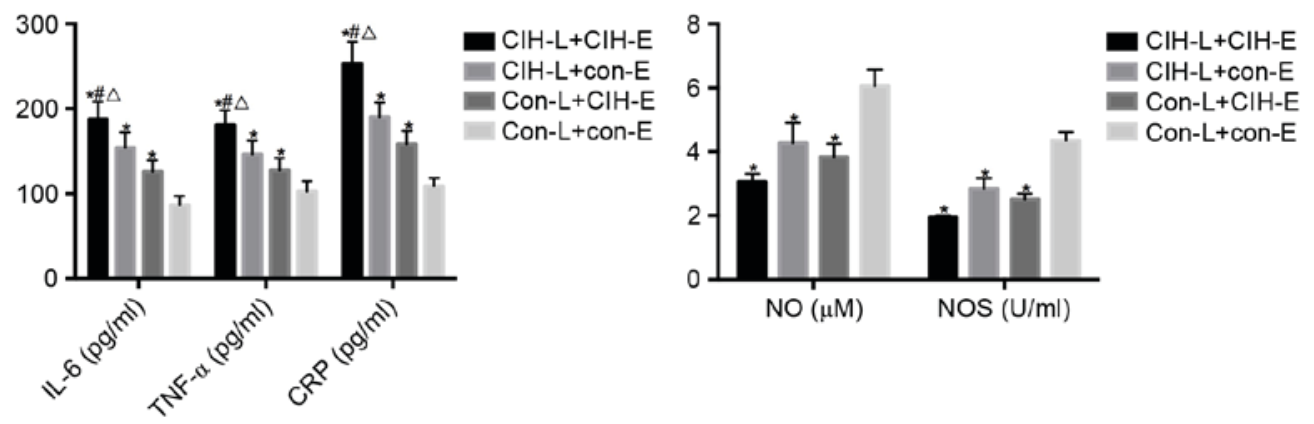

Figure 7. IL-6, TNF- $\alpha$, CRP, NO and NOS in the co-culture supernatant of rat lymphocytes and rat endotheliocytes. ${ }^{*} \mathrm{P}<0.05$ vs. CON-L+CON-E; ${ }^{*} \mathrm{P}<0.05$ vs. $\mathrm{CIH}-\mathrm{L}+\mathrm{CON}-\mathrm{E} ;{ }^{\wedge} \mathrm{P}<0.05$ vs. CON-L+CIH-E. CIH, chronic intermittent hypoxia; IL-6, interleukin-6; TNF- $\alpha$, tumor necrosis factor- $\alpha$; CRP, C-reactive protein; NO, nitric oxide; NOS, nitric oxide synthase; CON, control; L, lymphocytes; E, endotheliocytes.

the effect of CIH on SAP, DAP, MAP and HR. In the present study, it was observed that serum IL-6, TNF- $\alpha$ and CRP levels increased in $\mathrm{CIH}$ rats and lymphocytes, in addition to in rat endotheliocytes following $\mathrm{CIH}$ induction, compared with the control. Additionally, serum IL-6, TNF- $\alpha$ and CRP were demonstrated to be positively correlated with the incidence of $\mathrm{CIH}$ combined with hypertension in humans, in addition to the SAP, DAP, MAP and HR in CIH rats, suggesting that serum IL-6, TNF- $\alpha$ and CRP may be biomarkers of CIH combined with hypertension.

NO and NOS have been demonstrated to be involved in important regulatory on autonomic functions, particularly in regulating the expression of genes associated with hypoxia $(37,38)$. The present study detected the serum $\mathrm{NO}$ and NOS in rats at different timepoints, and it was observed that NO and NOS decreased gradually. The present study additionally analyzed the association between NO and NOS, and $\mathrm{CIH}$ combined with hypertension, and confirmed that NO and NOS were negatively correlated with SAP, DAP, MAP and HR in $\mathrm{CIH}$ rats. The results of the present study indicated that NO and NOS may be taken to be biomarkers for the diagnosis of $\mathrm{CIH}$ combined with hypertension.

However, the levels of NO and iNOS were increased in $\mathrm{CIH}$ rat lymphocytes compared with control cells, as did iNOS in rat endotheliocytes following $\mathrm{CIH}$ induction, while $\mathrm{NO}$ and eNOS decreased significantly in rat endotheliocytes following $\mathrm{CIH}$ induction. These results illustrated that the serum NO and NOS were predominantly derived from endotheliocytes. Although $\mathrm{CIH}$ induction induced the expression of iNOS, the influence on the total NO was less compared with decreasing eNOS expression.

However, there were limitations to the present study. The sample size in the investigation was small, and was focused on the Hakka people of Huizhou City without investigation other regions, which is likely to result in regional differences and inaccuracy of the correlations between $\mathrm{CIH}$ combined with hypertension and clinical data, hemodynamic alterations and serum factors. In addition, due to the limited time of the experiments, the rats were only fed for 21 days for the present study. Further investigations with longer experimental time and more measures are required.

In conclusion, age, male gender, BMI, smoking and T2DM history, and serum IL-6, TNF- $\alpha$ and CRP were positively correlated with $\mathrm{CIH}$ combined with hypertension, while NO and NOS were negatively correlated with CIH. Hakka patients exhibited less inflammation and OS in CIH combined with hypertension. Serum IL-6, TNF- $\alpha$, CRP, NO and NOS may be biomarkers for the diagnosis of $\mathrm{CIH}$ combined with hypertension, in addition to targets for the treatment or prevention of $\mathrm{CIH}$ or hypertension.

\section{References}

1. Caples SM, Gami AS and Somers VK: Obstructive sleep apnea. Ann Intern Med 142: 187-197, 2005.

2. Khayat R, Patt B and Hayes D Jr: Obstructive sleep apnea: The new cardiovascular disease. Part I: Obstructive sleep apnea and the pathogenesis of vascular disease. Heart Fail Rev 14: 143-153, 2009. 
3. Dempsey JA, Veasey SC, Morgan BJ and O'Donnell CP: Pathophysiology of sleep apnea. Physiol Rev 90: 47-112, 2010.

4. Fletcher EC: The relationship between systemic hypertension and obstructive sleep apnea: Facts and theory. Am J Med 98: 118-128, 1995.

5. Das AM and Khayat R: Hypertension in obstructive sleep apnea: Risk and therapy. Expert Rev Cardiovasc Ther 7: 619-626, 2009

6. Sala-Mercado JA, Spranger MD, Abu-Hamdah R, Kaur J, Coutsos M, Stayer D, Augustyniak RA and O'Leary DS Attenuated muscle metaboreflex-induced increases in cardiac function in hypertension. Am J Physiol Heart Circ Physiol 305: H1548-H1554, 2013

7. Ito $\mathrm{T}$, Ishikawa $\mathrm{E}$, Fujimoto $\mathrm{N}$, Okubo S, Ito G, Ichikawa T, Nomura $\mathrm{S}$ and Ito M: Effects of aliskiren on blood pressure and humoral factors in hypertensive hemodialysis patients previously on angiotensin II receptor antagonists. Clin Exp Hypertens 36 497-502, 2014

8. Chiasson VL, Munshi N, Chatterjee P, Young KJ and Mitchell BM: Pin1 deficiency causes endothelial dysfunction and hypertension. Hypertension 58: 431-438, 2011.

9. Morishita R: Is vascular endothelial growth factor a missing link between hypertension and inflammation? Hypertension 44 253-254, 2004

10. Mikami S, Nihira S and Takemori K: The construction of vascular information data base for efficient blood pressure measurement. Hirosaki Med J 41: 282-289, 1989.

11. Peng Y, Kline DD, Dick TE and Prabhakar NR: Chronic intermittent hypoxia enhances carotid body chemoreceptor response to low oxygen. Adv Exp Med Biol 499: 33-38, 2001.

12. Karamanlı H, Özol D, Ugur KS, Yıldırım Z, Armutçu F, Bozkurt B and Yigitoglu R: Influence of CPAP treatment on airway and systemic inflammation in OSAS patients. Sleep Breath 18: 251-256, 2014.

13. Svensson M, Venge P, Janson C and Lindberg E: Relationship between sleep-disordered breathing and markers of systemic inflammation in women from the general population. J Sleep Res 21: 147-154, 2012.

14. Kaviraj B, Bai SC, Liang SU, Zheng XO, Huang R, Li TP and Xu DL: Effect of obstructive sleep apnea syndrome on serum C-reactive protein level, left atrial size and premature atrial contraction. Nan Fang Yi Ke Da Xue Xue Bao 31: 197-200, 2011.

15. Chen J, Zhang J and Chen Y: Relationship between hs-CRP and obstructive sleep apnea in hypertension patients. Chin J Integr Med Cardio-/Cerebrovasc Dis, 2012.

16. McNicholas WT: Chronic obstructive pulmonary disease and obstructive sleep apnea: Overlaps in pathophysiology, systemic inflammation, and cardiovascular disease. Am J Respir Crit Care Med 180: 692-700, 2009

17. Jordan W, Cohrs S, Degner D, Meier A, Rodenbeck A, Mayer G Pilz J, Rüther E, Kornhuber J and Bleich S: Evaluation of oxidative stress measurements in obstructive sleep apnea syndrome. J Neural Transm (Vienna) 113: 239-254, 2005.

18. Pawar A, Nanduri J, Yuan G, Khan SA, Wang N, Kumar GK and Prabhakar NR: Reactive oxygen species-dependent endothelin signaling is required for augmented hypoxic sensory response of the neonatal carotid body by intermittent hypoxia. Am J Physiol Regul Integr Comp Physiol 296: R735-R742, 2009.

19. Lam SY and Leung PS: A locally generated angiotensin system in rat carotid body. Regul Pept 107: 97-103, 2002.

20. Iturriaga R, Villanueva $S$ and Mosqueira M: Dual effects of nitric oxide on cat carotid body chemoreception. J Appl Physiol (1985) 89: 1005-1012, 2000.

21. Alissa EM and Ferns GA: Functional foods and nutraceuticals in the primary prevention of cardiovascular diseases. J Nutr Metab 2012: 569486, 2012
22. Knox S, Theorell T, Malmberg BG and Lindqvist R: Stress management in the treatment of essential hypertension in primary health care. Scand J Prim Health Care 4: 175-181, 1986.

23. Resta O, Foschino-Barbaro MP, Legari G, Talamo S, Bonfitto P, Palumbo A, Minenna A, Giorgino R and De Pergola G: Sleep-related breathing disorders, loud snoring and excessive daytime sleepiness in obese subjects. Int J Obes Relat Metab Disord 25: 669-675, 2001.

24. Foster GE, Hanly PJ, Ahmed SB, Beaudin AE, Pialoux V and Poulin MJ: Intermittent hypoxia increases arterial blood pressure in humans through a Renin-Angiotensin system-dependent mechanism. Hypertension 56: 369-377, 2010.

25. Fletcher EC, Lesske J, Qian W, Miller CC III and Unger T: Repetitive, episodic hypoxia causes diurnal elevation of blood pressure in rats. Hypertension 19: 555-561, 1992.

26. Nanduri J, Peng YJ, Yuan G, Kumar GK and Prabhakar NR Hypoxia-inducible factors and hypertension: Lessons from sleep apnea syndrome. J Mol Med (Berl) 93: 473-480, 2015.

27. Palma DT, Philips GM, Arguedas MR, Harding SM and Fallon MB: Oxygen desaturation during sleep in hepatopulmonary syndrome. Hepatology 47: 1257-1263, 2008.

28. Drager LF, Jun JC and Polotsky VY: Metabolic consequences of intermittent hypoxia: Relevance to obstructive sleep apnea. Best Pract Res Clin Endocrinol Metab 24: 843-851, 2010.

29. Kapa S, Sert Kuniyoshi FH and Somers VK: Sleep apnea and hypertension: Interactions and implications for management. Hypertension 51: 605-608, 2008.

30. Morgan BJ, Crabtree DC, Puleo DS, Badr MS, Toiber F and Skatrud JB: Neurocirculatory consequences of abrupt change in sleep state in humans. J Appl Physiol (1985) 80: 1627-1636, 1996.

31. Tamisier R, Pépin JL, Rémy J, Baguet JP, Taylor JA, Weiss JW and Lévy P: 14 nights of intermittent hypoxia elevate daytime blood pressure and sympathetic activity in healthy humans. Eur Respir J 37: 119-128, 2011.

32. Wan NS, Chen BY, Feng J, Li S, Zhou W, Zhang Z and Guo R: The effects of chronic intermittent hypoxia on blood pressure and sympathetic nerve activity in rats. Zhonghua Jie $\mathrm{He} \mathrm{He} \mathrm{Hu}$ Xi Za Zhi 35: 29-32, 2012 (In Chinese).

33. Levy P, Tamisier R, Arnaud C, Monneret D, Baguet JP, Stanke-Labesque F, Dematteis M, Godin-Ribuot D, Ribuot C and Pepin JL: Sleep deprivation, sleep apnea and cardiovascular diseases. Front Biosci (Elite Ed) 4: 2007-2021, 2012.

34. Somers VK, White DP, Amin R, Abraham WT, Costa F, Culebras A, Daniels S, Floras JS, Hunt CE, Olson LJ, et al: Sleep apnea and cardiovascular disease: An American heart association/American college of cardiology foundation scientific statement from the American hear association council for high blood pressure research professional education committee, council on clinical cardiology, stroke council, and council on cardiovascular nursing. J Am Coll Cardiol 52: 686-717, 2008

35. Karamanlı H, Özol D, Ugur KS, Yıldırım Z, Armutçu F, Bozkurt B and Yigitoglu R: Influence of CPAP treatment on airway and systemic inflammation in OSAS patients. Sleep Breath 18: 251-256, 2014

36. Svensson M, Venge P, Janson $\mathrm{C}$ and Lindberg E: Relationship between sleep-disordered breathing and markers of systemic inflammation in women from the general population. J Sleep Res 21: 147-154, 2012.

37. Rus A, Del Moral ML, Molina F and Peinado MA: Upregulation of cardiac NO/NOS system during short-term hypoxia and the subsequent reoxygenation period. Eur J Histochem 55: e17, 2011.

38. Ren W, Yang X, Jiang X, Li Z and Zhang Z: Chronic hypoxia and exercise training affect the NO content and NOS activity of rat skeletal muscle: Original research article. Int SportMed J 11: 244-257, 2010 . 